\title{
Investigation of Pyrometallurgical Silicon Slags
}

\author{
Nina V. Nemchinova*, \\ Andrey A. Tiutrin and Tatyana A. Buzikova \\ Irkutsk State Technical University \\ 83 Lermontov, Irkutsk, 664074, Russia
}

Received 10.02.2015, received in revised form 29.03.2015, accepted 30.05.2015

The smelted in electric arc furnaces silicon contains impurities which remove by oxidative refining in the ladle blowing air in industry. Due to the increasing demands to the melted silicon quality is necessary to search a new ways to decrease the impurities content, whose concentration in the final product is insignificant. According published data and industrial practices analysis the main components of the refining slag are calcium, aluminum and silicon oxides with silicon carbide inclusions and silicon. However, according different analysis types it was found the slag has a complex composition. And there is no The information about a possible mechanism of the inclusions formation in this product of pyrometallurgical process is absent. Therefore, the aim of our investigations was to develop thermodynamic technique of the oxide inclusions formation in the slag based on computer formation of ternary state diagram.

Keywords: silicon, refining, slag, crystallization, modeling state diagram, eutectic.

\section{Исследование шлаков пирометаллургии кремния}

\author{
Н.В. Немчинова, \\ А.А. Тютрин, Т.А. Бузикова \\ Иркутский государственный технический университет \\ Россия, 664074, Иркутск, Лермонтова, 83
}

Получаемый в рудно-термических печах кремний содержит примеси, для удаления которых в промышленных условиях проводят окислительное рафинирование в ковще продувкой воздухом. В связи с повышением требований к качеству выплавляемого кремния необходимо осуществить поиск новых путей снижения содержания примесей, концентрация которых в готовом продукте не столь значительна. Анализ литературных данных и результатов производственной практики показал, что основными составляющими рафинировочного шлака являются оксиды кальция, алюминия и кремния с включениями карбида кремния и корольками собственно кремния. Однако по данным различных видов анализа установлено, что шлак имеет сложный состав. И отсутствует информация о возможном механизме образования

(c) Siberian Federal University. All rights reserved

* Corresponding author E-mail address: ninavn@yandex.ru 
включений в данном продукте пирометаллургического процесса. Поэтому иелью наших исследований явилась разработка методики термодинамического анализа формирования оксидных включений в шлаке на основе компьютерного построения диаграмм плавкости тройных систем.

Ключевые слова: кремний, рафинирование, илак, кристаллизация, моделирование, диаграмма состояния, эвтектика.

\section{Введение}

Получаемый в рудно-термических печах (РТП) кремний содержит примеси, для устранения которых в промышленных условиях проводят окислительное рафинирование в ковше продувкой воздухом. Источниками поступления примесей служат сырьевые материалы (кварц, кварцит, различные углеродистые восстановители - каменный уголь, нефтекокс, древесный уголь, древесная щепа) $[1,2]$. При этом операция по очистке направлена преимущественно на снижение содержания основных примесей (Al, Ca, Ti) и удаление шлаковых включений. В связи с повышением требований к качеству выплавляемого кремния (в частности, по содержанию $\mathrm{P}, \mathrm{B}, \mathrm{Bi}, \mathrm{Ni}, \mathrm{Na}$ и др.) необходимо осуществить поиск новых путей снижения содержания и тех примесей, концентрация которых в готовом продукте не столь значительна. Для этого необходимо знать, как распределяются примеси в процессе рафинирования и каков механизм их перехода в рафинировочный шлак.

Анализ литературных данных и результатов производственной практики показал, что основными составляющими рафинировочного шлака являются оксиды кальция, алюминия и кремния с включениями карбида кремния и корольками собственно кремния [3]. Однако на основании данных различных видов анализа установлено, что шлак имеет сложный состав. И отсутствует информация о возможном механизме образования включений в данном продукте пирометаллургического процесса. Поэтому целью наших исследований стала разработка методики термодинамического анализа формирования оксидных включений в шлаке на основе компьютерного построения диаграмм плавкости тройных систем.

\section{Исследования состава шлака}

Процесс получения кремния в РТП относится к бесшлаковым процессам, однако, как у любого пирометаллургического процесса, незначительное количество шлаковой фазы всетаки образуется. В исследуемом процессе шлак - продукт недовосстановления кремнезема и оксидов-примесей. Содержание шлака (его называют печным) в кремнии достигает 1-3 \% у маломощных однофазных печей и 5-8 \% - у мощных трехфазных, что снижает извлечение кремния на 1,2 и $2,2 \%$ соответственно $[1,4]$.

Часть оксидов, поступающих в РТП с шихтовыми материалами, в силу высокого сродства к кислороду не успевают восстановиться в процессе электроплавки [5] и образуют шлаковую фазу, которая запутывается в кремнии при его выпуске из печи (рис. 1).

В шлаке в среднем содержится, мас. \%, до $15 \mathrm{Si}, 33-47 \mathrm{SiO}_{2}$ и $6,5-25 \mathrm{SiC}$, а также $\mathrm{Al}_{2} \mathrm{O}_{3}$ и $\mathrm{CaO}$, что указывает на незавершенность восстановления кремнезема в горне РТП - главного компонента шихты. При разрушении солей, имеющих в своем составе алюминий и кальций и попадающих в шахту печи с сырьевыми материалами, образуются сложные по составу ту-

$$
-458-
$$




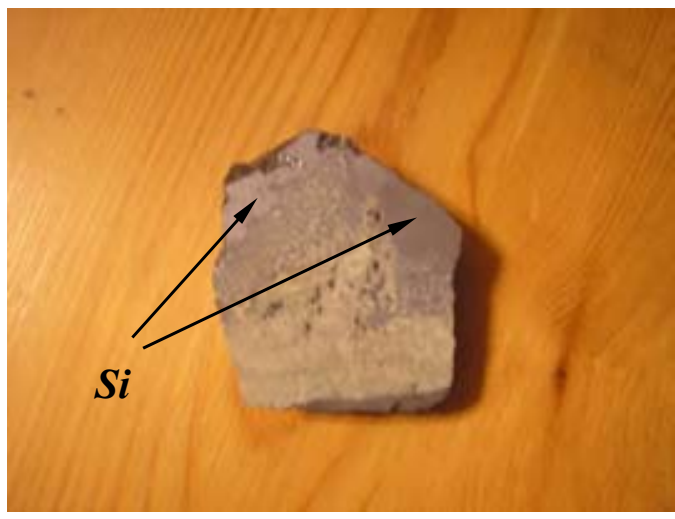

Рис. 1. Шлак леточного отверстия (микрошлиф)

гоплавкие шлаки. Трудновосстановимые оксиды из шихтовых материалов частично восстанавливаются в процессе плавки, а невосстановленная часть образует с попавшим на подину кремнеземом подовую настыль, представляющую собой сложные составные (комплексные) шлаки типа анортита $\mathrm{CaO} \cdot \mathrm{Al}_{2} \mathrm{O}_{3} \cdot 2 \mathrm{SiO}_{2}$, геленита $2 \mathrm{CaO} \cdot \mathrm{Al}_{2} \mathrm{O}_{3} \cdot \mathrm{SiO}_{2}$, алита $8 \mathrm{CaO} \cdot \mathrm{Al}_{2} \mathrm{O}_{3} \cdot 2 \mathrm{SiO}_{2}$. Coстав подовой настыли в РТП разнообразен и зависит от мощности печи и состава загружаемых в процесс шихтовых материалов. В среднем настыль содержит, мас. \%: 18-44 $\mathrm{SiO}_{2}, 20-67 \mathrm{CaO}$, $15-37 \mathrm{Al}_{2} \mathrm{O}_{3}$. Температура шлаков подовой настыли достигает $1600{ }^{\circ} \mathrm{C}$, шлаки являются вязкими и тугоплавкими. При выпуске расплава кремния из печи с потоком захватываются примеси из подовой настыли в нижней части РТП.

Попадание шлака в горн и далее в кремний при его выпуске может быть следствием недовосстановления шихты в зоне максимальной температуры из-за недостатка углерода, неравномерности загрузки и провалов шихты, быстрого стекания расплава [1]. Недостаточному восстановлению кремнезема из шлака может также способствовать снижение его активности в расплаве, нарушение контакта между шлаком и восстановителем. Прекращение восстановления на подине печи может быть только следствием недостаточного перегрева шлака, находящегося под слоем легкого жидкого кремния.

Основные пути снижения содержания комплексного шлака в кремнии - осуществление непрерывного и равномерного схода в зону высокой температуры шихты оптимального состава, быстрое и полное восстановление кремнезема, исключение провалов больших количеств шихты при редких опиковках колошника [1].

Для получения кремния металлургических марок, отвечающего требованиям современных потребителей, на ЗАО «Кремний» ОК «РУСАЛ» (г. Шелехов, Иркутская обл.) - крупнейшем в России предприятии в данной отрасли - предусмотрено рафинирование окислением металлов-примесей продувкой расплава воздухом. При данном способе очистки в первую очередь окисляются примеси с ме́ньшей упругостью диссоциации, поэтому барботированием кремниевого расплава проводят рафинирование в основном от алюминия и кальция:

$$
\begin{aligned}
2 \mathrm{Al}+1,5 \mathrm{O}_{2} & =\mathrm{Al}_{2} \mathrm{O}_{3}+31006 \text { кДж; } \\
\mathrm{Ca}+0,5 \mathrm{O}_{2}=\mathrm{CaO}+15922 \text { кДж; } & -459-
\end{aligned}
$$




$$
\begin{aligned}
& 2 \mathrm{Al}+1,5 \mathrm{SiO}_{2}=1,5 \mathrm{Si}+\mathrm{Al}_{2} \mathrm{O}_{3}+5028 \text { кДж; } \\
& 2 \mathrm{Ca}+\mathrm{SiO}_{2}=\mathrm{Si}+2 \mathrm{CaO}+4609 \text { кДж. }
\end{aligned}
$$

Химический анализ включений в рафинированном кремнии $\left(\mathrm{Si}_{\text {paф }}\right)$ выполнен методом PCMA на электронно-зондовом рентгеноспектральном микроанализаторе «Superprobe-8200» фирмы Jeol (Япония). Как известно, в данном методе анализа выход обратно рассеянных отраженных электронов (их число) является функцией атомного номера элемента. Регистрация отраженных электронов или изменения плотности тока позволяет получить картину распределения элементов в приповерхностном слое образца. Вторичные электроны, испускаемые образцом в результате неупругих столкновений пучка электронов с атомами мишени, несут информацию о рельефе поверхности и позволяют изучать морфологию объектов, так называемые картины в SEI. Часть электронов (называемые обратно рассеянными) проникают в глубину образца, рассеиваются в результате упругого столкновения с атомами мишени и выходят на поверхность. Данные электроны несут информацию как о составе включения (СОМРО - контраст по атомному номеру), так и о его топографии (ТОРО - топографический контраст) [6].

Углерод присутствует в кремнии в виде карборунда $(\mathrm{SiC})$ или в свободном состоянии. Связь «Si-C» очень прочная, карбид кремния разрушается только при высокой температуре выше $1700{ }^{\circ} \mathrm{C}$ - с помощью $\mathrm{SiO}_{\text {газ }}$ и $\mathrm{SiO}_{2 т в}$. Накопление $\mathrm{SiC}$ может происходить под влиянием избытка восстановителя и снижения температуры $[4,7]$.

Нами были исследованы несколько образцов рафинировочного шлака с предприятия ЗАО «Кремний» ОК «Русал» (г. Шелехов, Иркутская обл.), отобранных из рафинировочного ковша вместимостью 2400 кг кремния, при нормальном технологическом режиме РТП. Один образец - из печи после планово-предупредительного ремонта (ППР). Данные рентгеноспектрального (с помощью рентгеновского спектрометра ARL 9900) и химического анализов исследуемых образцов шлака приведены в табл. 1.

Наиболее оптимальный состав шлака для полного его отделения от расплава кремния должен составлять в среднем, мас. \%, соответственно: $69 \mathrm{SiO}_{2}, 18 \mathrm{Al}_{2} \mathrm{O}_{3}, 13 \mathrm{CaO}$ [3]. Данный шлак

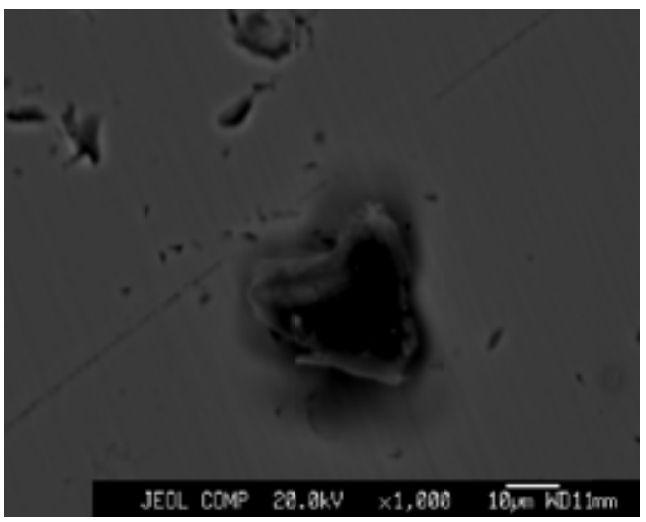

a

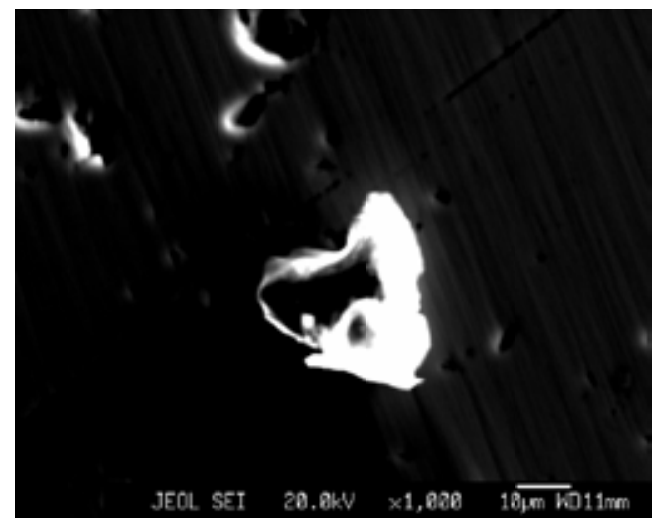

6

Рис. 2. Включения карбида кремния (1) и оксикарбида кремния (2) в техническом кремнии, увеличение х1000 (данные РСМА): a - светлое поле (режим СОМРО); б - темное поле (режим SEI) 
Таблица 1. Химический состав шлаков после окислительного рафинирования, мас. \%

\begin{tabular}{|c|c|c|c|c|c|}
\hline Элементы & РТП-1 & РТП-2 & $\begin{array}{c}\text { РТП-3 } \\
\text { (после ППР) }\end{array}$ & $\begin{array}{c}\text { РТП-3 } \\
\text { (норм.ход) }\end{array}$ & РТП-6 \\
\hline $\mathrm{SiO}_{2}$ & 39,80 & 55,60 & 69,80 & 39,60 & 44,80 \\
\hline $\mathrm{SiC}$ & 11,90 & 10,50 & 7,80 & 7,40 & 5,00 \\
\hline $\mathrm{CaO}$ & 20,60 & 15,40 & 8,35 & 30,90 & 24,10 \\
\hline $\mathrm{Al}_{2} \mathrm{O}_{3}$ & 13,40 & 6,45 & 5,06 & 13,40 & 18,80 \\
\hline $\mathrm{Fe}_{2} \mathrm{O}_{3}$ & 0,16 & 0,10 & 0,11 & 0 & 0,31 \\
\hline Прочие & 14,14 & 11,95 & 8,88 & 8,60 & 6,99 \\
\hline
\end{tabular}

позволяет поддерживать содержание кальция в среднем 0,026 мас. \% в кремнии. При снижении содержания кальция до 0,01 мас. \% иногда возникают трудности рафинирования из-за всплытия шлака. При данном явлении очень трудно избежать перемешивания шлака с расплавом кремния во время разливки (это приводит к появлению шлаковых включений). Целенаправленная подача кварцевого песка (флюса) перед разливкой позволяет коагулировать мелкие капли шлака на зернах данного флюса, которые из-за бо́льшей плотности, чем расплав кремния, соединяются с донным шлаком.

По данным металлографического (рис. 3) и рентгенофазового (рис. 4) анализов, в шлаковой фазе фиксируются интерметаллические соединения в общей структуре оксидов и карборунда [3].

Как было показано, шлак по своему составу имеет сложную структуру, для изучения которой нами была предложена термодинамическая методика изучения механизма формирования включений на основе компьютерного построения диаграмм плавкости тройных систем. Ранее нами были проведены исследования по анализу образования примесных включений в кремнии $[8,9]$. В данной работе мы рассматриваем малоизученные тройные диаграммы « $\mathrm{Na}_{2} \mathrm{O}-\mathrm{CaO}-\mathrm{SiO}_{2} »$, « $\mathrm{SiO}_{2}-\mathrm{Al}_{2} \mathrm{O}_{3}-\mathrm{P}_{2} \mathrm{O}_{5} »$, « $\mathrm{SiO}_{2}-\mathrm{B}_{2} \mathrm{O}_{3}-\mathrm{FeO}$ », на основе которых возможно формирование оксидных включений, которые могут присутствовать в рафинировочном шлаке.

\section{Построение и анализ тройных диаграмм плавкости оксидных систем}

Для решения поставленной задачи в наших исследований была использована компьютерная программа «Diatris 1.2», предназначенная для расчета и графического изображения диаграмм плавкости тройных систем в приближении регулярного раствора. Основой программы служит термодинамический метод расчета параметров ликвидуса тройной системы в точке с заданными концентрациями компонентов по модели регулярного раствора [8].

Для построения диаграммы состояния « $\mathrm{Na}_{2} \mathrm{O}-\mathrm{CaO}-\mathrm{SiO}_{2} »$ (рис. 5) была сформирована база данных на основе бинарных диаграмм плавкости (температура плавления, молекулярные веса соединений и др.). Построенная диаграмма разбита на элементарные треугольники сосуществующих фаз, обозначенные пунктирными линиями, и на поля кристаллизации, ограниченные точками эвтектик. 

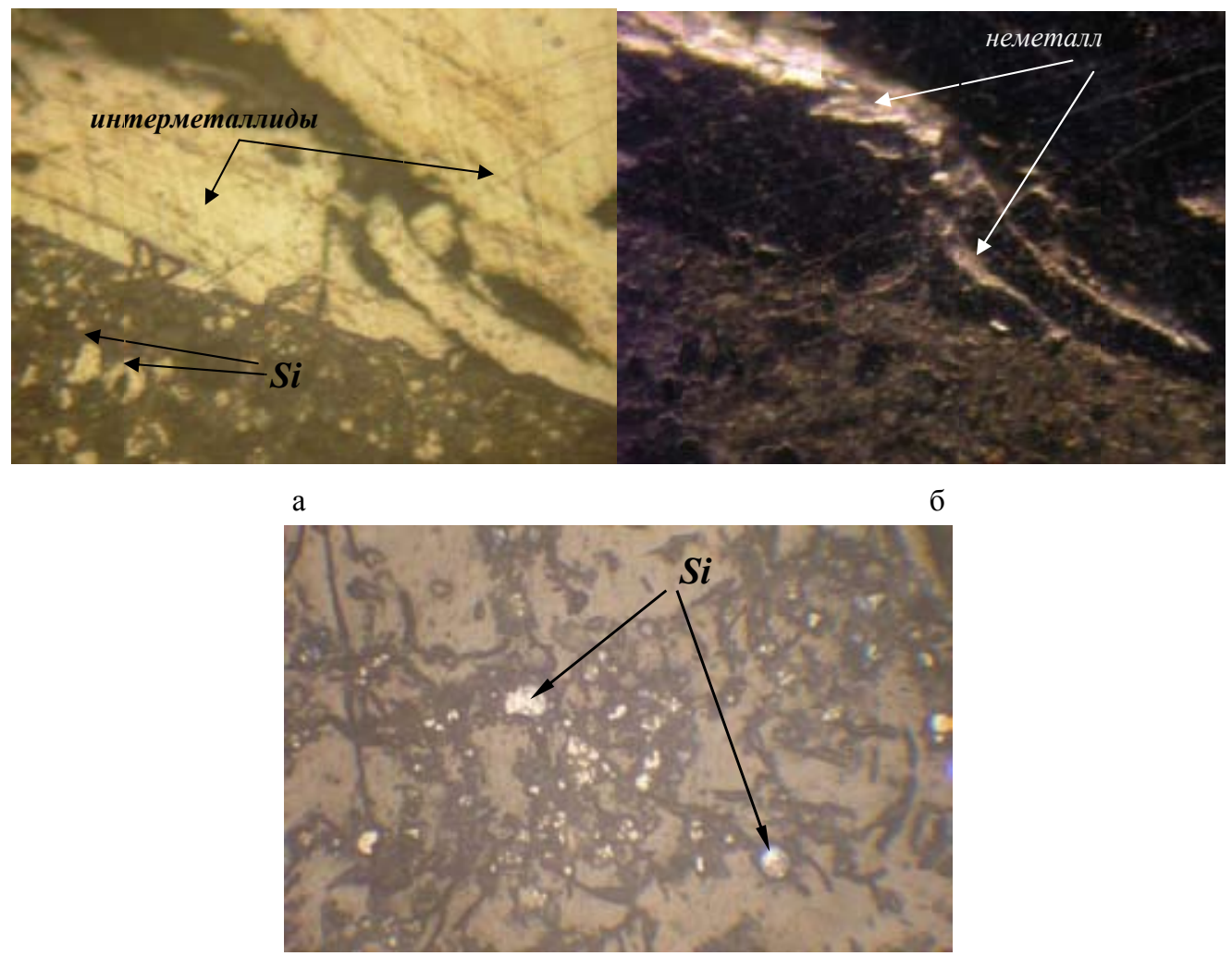

B

Рис. 3. Виды включений в шлаке, увеличение - х100: а - интерметаллиды (светлое поле); б - неметаллические включения (темное поле); в - корольки кремния в структуре шлака (светлое поле)

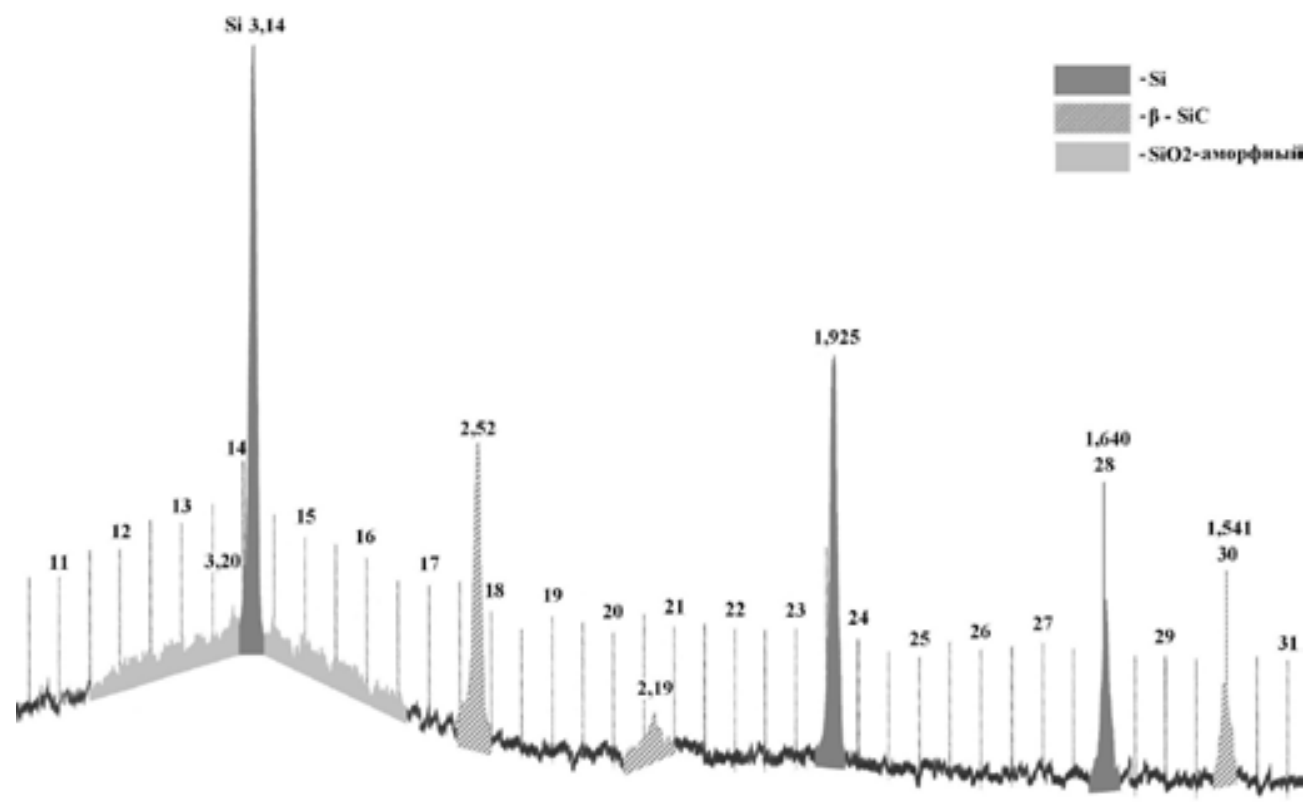

Рис. 4. Фрагмент дифрактограммы образца рафинировочного шлака 


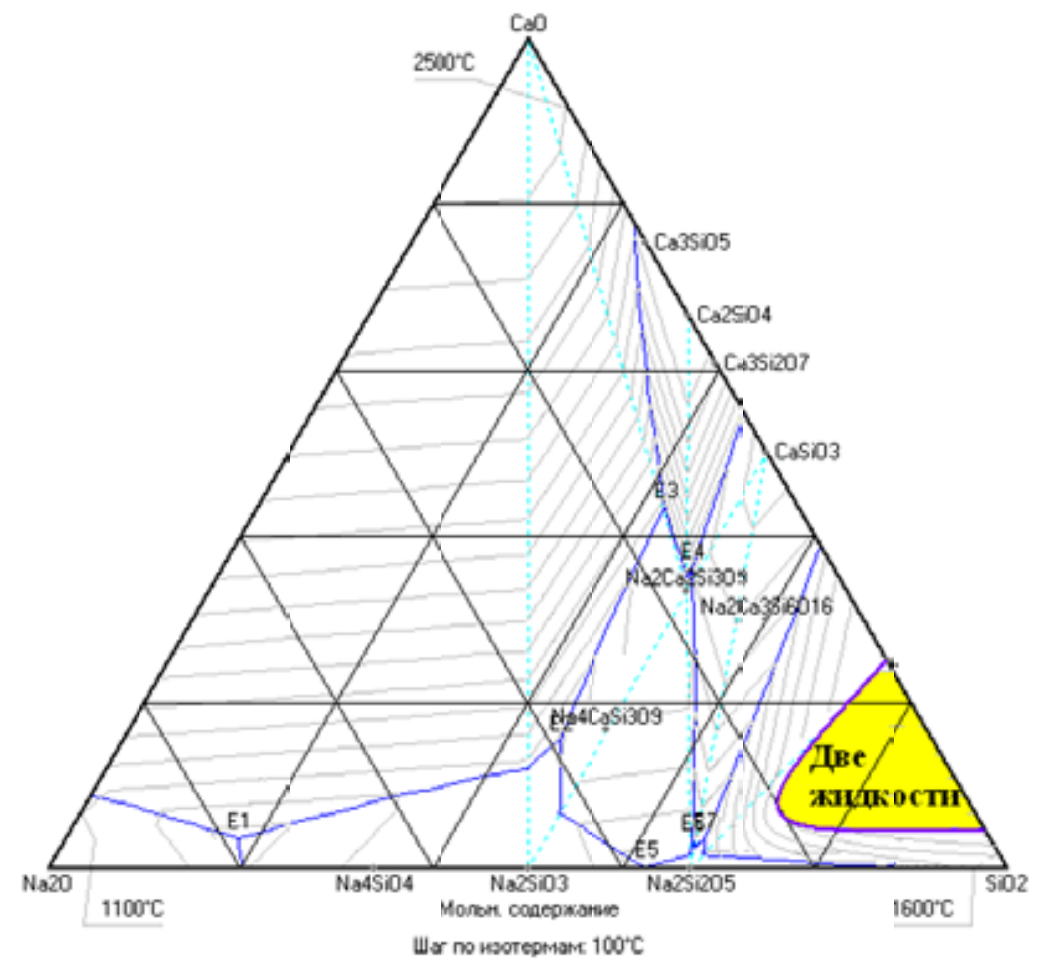

Рис. 5. Диаграмма состояния « $\mathrm{Na}_{2} \mathrm{O}-\mathrm{CaO}-\mathrm{SiO}_{2} »$, построенная с помощью компьютерной программы «Diatris $1.2 »$

Для изучения влияния скорости изменения температуры смеси на формирование шлака были проведены расчеты темпа кристаллизации в данной трехкомпонентной оксидной системе. Нами в изучаемой системе были выбраны три состава, кристаллизацию которых с равным шагом изменения температуры мы и рассматривали.

Состав 1, мол. доли, соответственно: $\mathrm{Na}_{2} \mathrm{O}-0,332, \mathrm{CaO}-0,335, \mathrm{SiO}_{2}-0,331$. Начальная температура ликвидуса $1697,7^{\circ} \mathrm{C}$. Состав 2 был выбран при содержании $\mathrm{SiO}_{2} \approx 0,9$ мол. доли, но так как заданный состав находится в области ликвации, то кристаллизации кристобалита не происходит и в реальном образце будет образовываться двухфазное стекло. Состав 3 , мол. доли, соответственно: $\mathrm{Na}_{2} \mathrm{O}-0,04, \mathrm{CaO}-0,48, \mathrm{SiO}_{2}-0,48$ (начальная температура ликвидуса $\left.1463,3^{\circ} \mathrm{C}\right)$. На рис. 6 приведены параметры расчета пути кристаллизации выбранных составов шлака.

При охлаждении шлака с составом 1 наблюдается равномерное увеличение содержания твердой фазы (рис. $6 a$ ), далее шлак будет кристаллизоваться при температуре $844,85^{\circ} \mathrm{C}$ в точке тройной эвтектики, отвечающей составу, мол. доли, соответственно: $\mathrm{Na}_{2} \mathrm{O}-0,784, \mathrm{CaO}-0,036$, $\mathrm{SiO}_{2}-0,171$.

При кристаллизации смеси состава 3 с низким содержанием натрия путь кристаллизации имеет иной характер (рис. 6б), и темп кристаллизации также меняет свой характер при достижении прямой ликвидуса $\left(1400^{\circ} \mathrm{C}\right)$ : он начинает снижаться и лишь при $1280{ }^{\circ} \mathrm{C}$ начинает вновь возрастать. Далее смесь будет кристаллизоваться при температуре $844,85{ }^{\circ} \mathrm{C}$ в точке тройной 


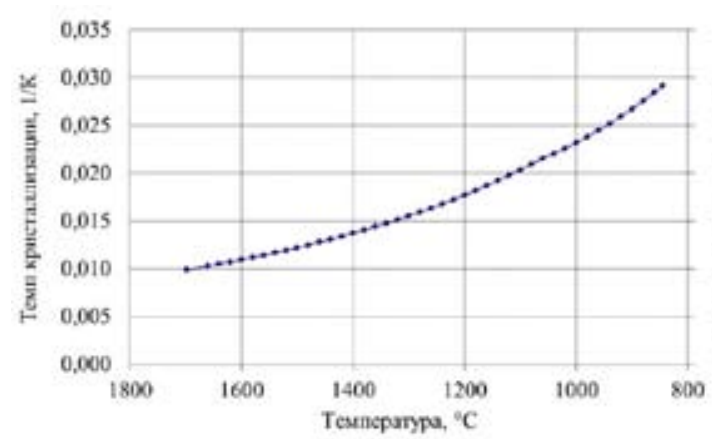

a

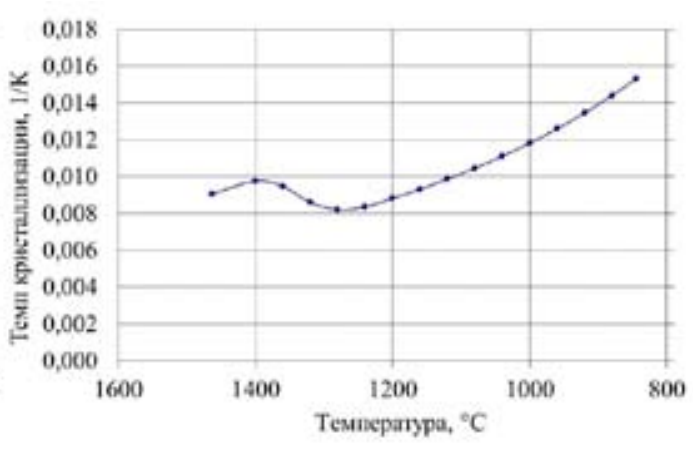

6

Рис. 6. Параметры расчета темпа кристаллизации рафинировочного шлака в системе « $\mathrm{Na}_{2} \mathrm{O}-\mathrm{CaO}-\mathrm{SiO} \mathrm{O}_{2} »$ : а - для состава $1 ;$ б - для состава 3

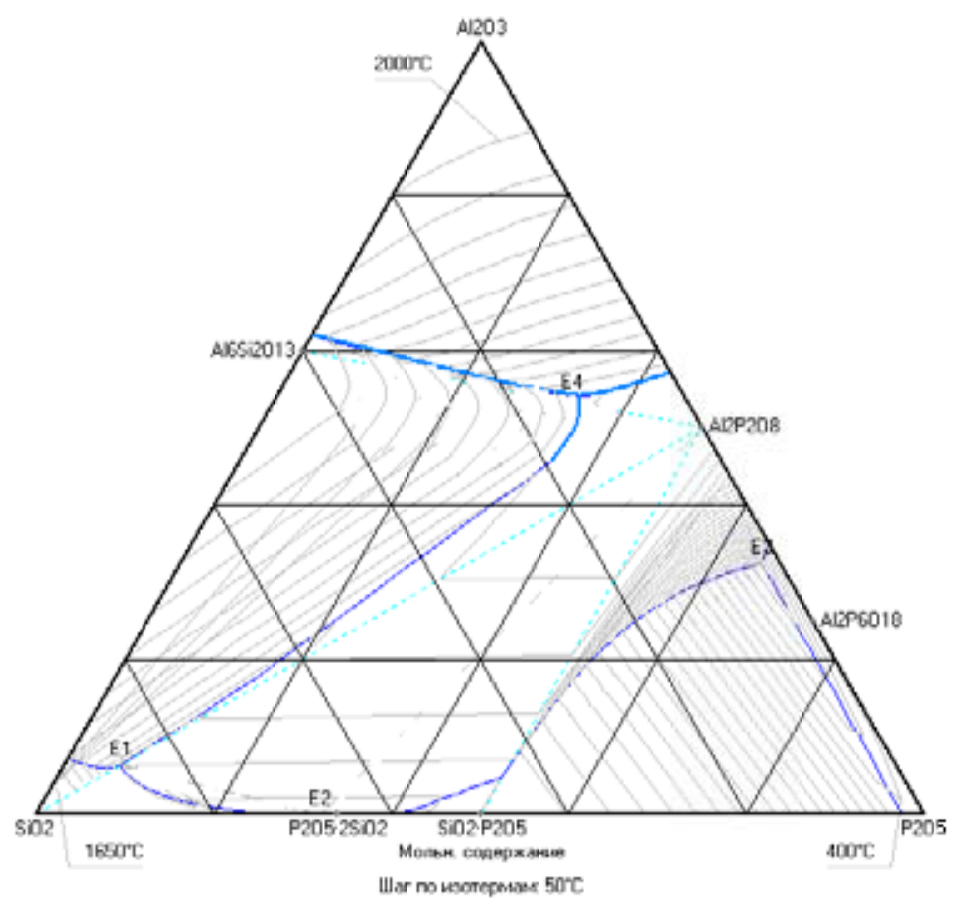

Рис. 7. Диаграмма состояния « $\mathrm{SiO}_{2}-\mathrm{Al}_{2} \mathrm{O}_{3}-\mathrm{P}_{2} \mathrm{O}_{5} »$, построенная с помощью компьютерной программы «Diatris $1.2 »$

эвтектики, отвечающей составу, мол. доли: $\mathrm{Na}_{2} \mathrm{O}-0,784, \mathrm{CaO}-0,036, \mathrm{SiO}_{2}-0,171$, как и смесь с составом 1.

Для изучения механизма образования и кристаллизации шлака, содержащего оксиды кремния, алюминия и фосфора, была построена диаграмма состояния тройной системы « $\mathrm{SiO}_{2}-$ $\mathrm{Al}_{2} \mathrm{O}_{3}-\mathrm{P}_{2} \mathrm{O}_{5}$ ». Данная диаграмма разбита на четыре элементарных треугольника сосуществующих фаз, и получено столько же точек тройных эвтектик, отвечающих различным составам (рис. 7). 


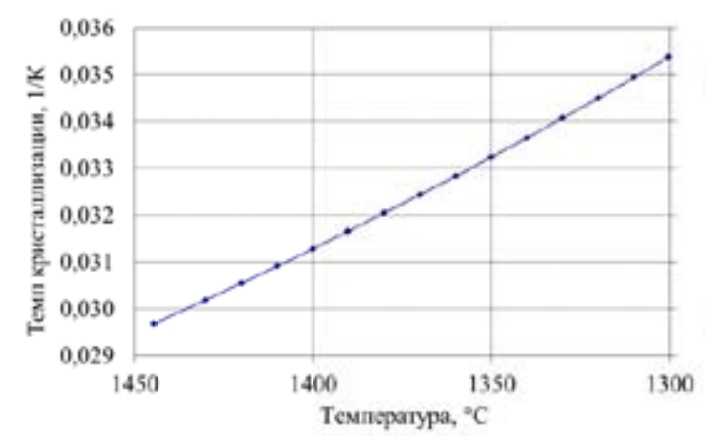

a

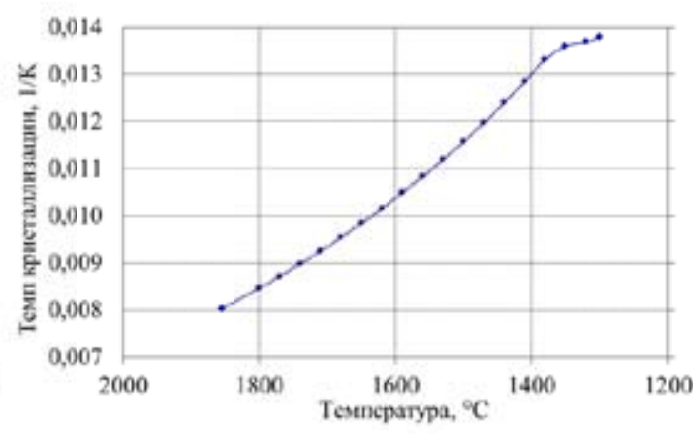

б

Рис. 8. Параметры расчета темпа кристаллизации рафинировочного шлака в системе « $\mathrm{SiO}_{2}-\mathrm{Al}_{2} \mathrm{O}_{3}-\mathrm{P}_{2} \mathrm{O}_{5} »$ : а - для состава $1 ;$ б - для состава 2

В изучаемой системе нами были выбраны два различных по содержанию оксидов состава, мол. доли, соответственно: состав $1\left(\mathrm{SiO}_{2}-0,9, \mathrm{Al}_{2} \mathrm{O}_{3}-0,046, \mathrm{P}_{2} \mathrm{O}_{5}-0,052\right.$; начальная температура ликвидуса $\left.-1444,6^{\circ} \mathrm{C}\right)$; состав $2\left(\mathrm{SiO}_{2}-0,48, \mathrm{Al}_{2} \mathrm{O}_{3}-0,479, \mathrm{P}_{2} \mathrm{O}_{5}-0,04\right.$ с начальной температура ликвидуса $\left.-1855,7^{\circ} \mathrm{C}\right)$. Параметры расчета пути кристаллизации выбранных составов рафинировочного шлака приведены на рис. 8 .

При охлаждении шлака с составом 1 наблюдается равномерное увеличение твердой фазы (рис. 8a), далее шлак будет кристаллизоваться при температуре $1300,3{ }^{\circ} \mathrm{C}$ в точке тройной эвтектики, отвечающей составу, мол. доли: $\mathrm{SiO}_{2}-0,873, \mathrm{Al}_{2} \mathrm{O}_{3}-0,059, \mathrm{P}_{2} \mathrm{O}_{5}-0,066$. При охлаждении смеси состава 2 также наблюдается равномерное увеличение твердой фазы (рис. 8б), кристаллизация шлака происходит в той же точке тройной эвтектики и температуре, как и кристаллизация смеси состава 1.

Также большой интерес при изучении механизма образования включений при кристаллизации шлака имеет диаграмма « $\mathrm{SiO}_{2}-\mathrm{B}_{2} \mathrm{O}_{3}-\mathrm{FeO} »$ (рис. 9).

В данной системе нами также были выбраны три состава. Состав 1 с начальной температурой ликвидуса $1701{ }^{\circ} \mathrm{C}$ и содержанием, мол. доли, соответственно: $\mathrm{SiO}_{2}-0,332, \mathrm{~B}_{2} \mathrm{O}_{3}-$ $0,335, \mathrm{FeO}-0,331$ (рис. 10а). Состав 2 был выбран при содержании $\mathrm{SiO}_{2} \approx 0,9$ мол. доли, но так как данный состав находится в области ликвации, то кристаллизация кристобалита не происходит, и в реальном образце будет образовываться двухфазное стекло. Состав 3 , мол. доли, соответственно: $\mathrm{SiO}_{2}-0,052, \mathrm{~B}_{2} \mathrm{O}_{3}-0,046, \mathrm{FeO}-0,9$. Начальная температура ликвидуса $1338,5^{\circ} \mathrm{C}$ (рис. 10б).

Темп кристаллизации данных смесей отличается лишь характером увеличения твердой фазы: так, при кристаллизации оксидов состава 1 изучаемый показатель резко увеличивается при низких температурах, тогда как темп кристаллизации смеси состава 3 равномерно возрастает на протяжении всего температурного интервала охлаждения. Также данные включения формируются при различных температурах и составах эвтектик: шлак 1 при температуpe $380,64{ }^{\circ} \mathrm{C}$ и эвтектике с содержанием, мол. доли, соответственно: $\mathrm{SiO}_{2}$ 0,002, $\mathrm{B}_{2} \mathrm{O}_{3}-0,365$, $\mathrm{FeO}$ - 0,632; шлак состава 3 - при температуре $1338,5^{\circ} \mathrm{C}$ и эвтектике, содержащей, мол. доли, соответственно: $\mathrm{SiO}_{2}-0,052, \mathrm{~B}_{2} \mathrm{O}_{3}-0,046, \mathrm{FeO}-0,9$.

$$
-465-
$$




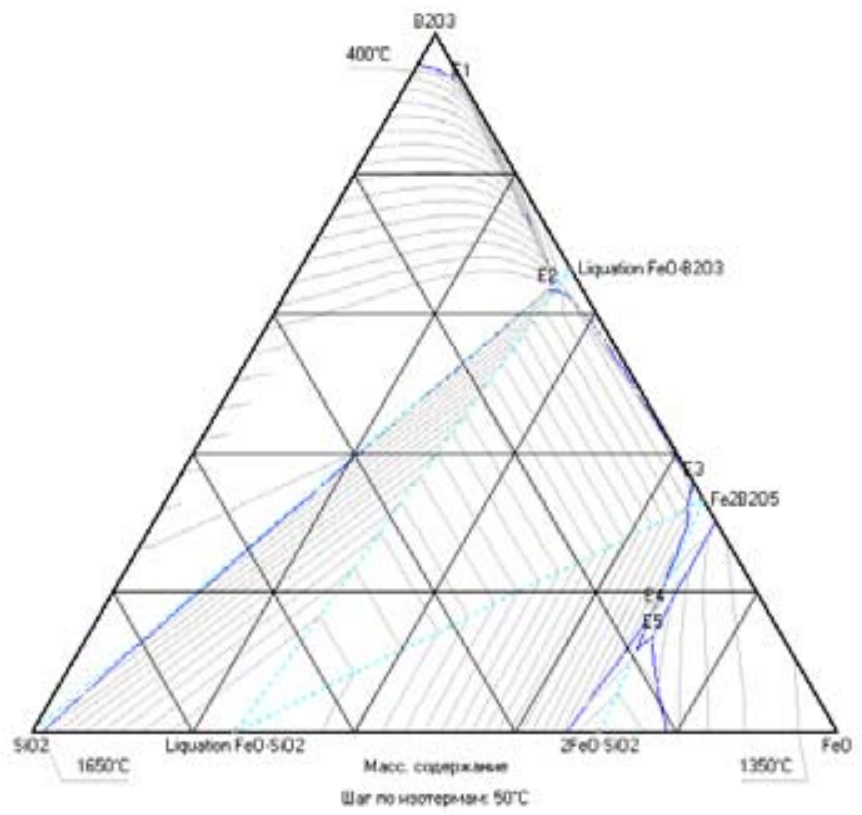

Рис. 9. Диаграмма состояния « $\mathrm{SiO}_{2}-\mathrm{B}_{2} \mathrm{O}_{3}-\mathrm{FeO} »$, построенная с помощью компьютерной программы «Diatris $1.2 »$

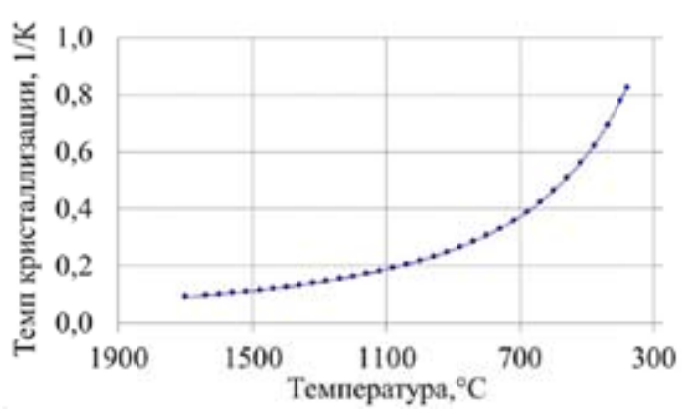

a

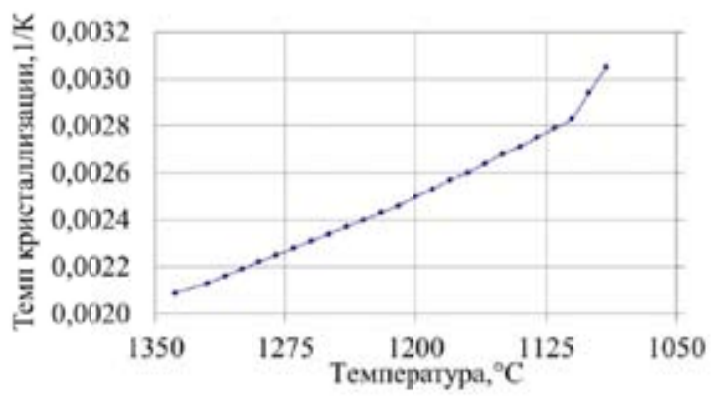

6

Рис. 10. Параметры расчета темпа кристаллизации рафинировочного шлака в системе « $\mathrm{SiO}_{2}-\mathrm{B}_{2} \mathrm{O}_{3}-\mathrm{FeO}$ »: а - для состава $1 ;$ б - для состава 3

\section{Выводы}

1. Исследован состав рафинировочного шлака карботермического процесса получения кремния, в котором обнаружены оксиды кремния, кальция, алюминия и в незначительном количестве железа. Кроме того, в шлаке присутствует карбид кремния в количестве 5,0-11,9 мас. \%, включения металлического кремния, сложные интерметаллические и неметаллические включения.

2. Разработана и предложена методика термодинамического анализа (на основе компьютерного построения диаграмм плавкости трехкомпонентных систем) формирования эвтектических примесных включений в рафинировочном шлаке с учетом выбора первоначальных со- 
ставов химической смеси и шага изменения (понижения) температуры кремниевого расплава после окислительного рафинирования при его кристаллизации.

3. На основе предложенной методики изучены механизмы формирования оксидных эвтектик в рафинировочном шлаке в системах « $\mathrm{Na}_{2} \mathrm{O}-\mathrm{CaO}-\mathrm{SiO}_{2} »$, « $\mathrm{SiO}_{2}-\mathrm{Al}_{2} \mathrm{O}_{3}-\mathrm{P}_{2} \mathrm{O}_{5}$ », « $\mathrm{SiO}_{2}-\mathrm{B}_{2} \mathrm{O}_{3}$ $\mathrm{FeO}$ ». Установлено, что расплав шлака в системе « $\mathrm{Na}_{2} \mathrm{O}-\mathrm{CaO}-\mathrm{SiO}_{2}$ » будет кристаллизоваться при температуре $844,85^{\circ} \mathrm{C}$ в точке тройной эвтектики, отвечающей составу, мол. доли: $\mathrm{Na}_{2} \mathrm{O}-$ 0,784, $\mathrm{CaO}-0,036, \mathrm{SiO}_{2}-0,171 ;$ в системе « $\mathrm{SiO}_{2}-\mathrm{Al}_{2} \mathrm{O}_{3}-\mathrm{P}_{2} \mathrm{O}_{5} »-$ при температуре $1300,3{ }^{\circ} \mathrm{C}$ в точке тройной эвтектики, отвечающей составу, мол. доли: $\mathrm{SiO}_{2}-0,873, \mathrm{Al}_{2} \mathrm{O}_{3}-0,059, \mathrm{P}_{2} \mathrm{O}_{5}-0,066$. Также в системе « $\mathrm{SiO}_{2}-\mathrm{B}_{2} \mathrm{O}_{3}-\mathrm{FeO}$ » составы формируются при различных температурах и составах эвтектик: шлак состава 1 при температуре $380,64^{\circ} \mathrm{C}$ и составе эвтектики, мол. доли: $\mathrm{SiO}_{2-} 0,002$, $\mathrm{B}_{2} \mathrm{O}_{3}-0,365, \mathrm{FeO}-0,632$; шлак состава 3 - при температуре $1338,5^{\circ} \mathrm{C}$ и составе эвтектики, мол. доли: $\mathrm{SiO}_{2}-0,052, \mathrm{~B}_{2} \mathrm{O}_{3}-0,046, \mathrm{FeO}-0,9$.

\section{Список литературы}

[1] Архипов С.В., Тупищын А.А., Катков О.М., Руш Е.А., Седых И.М. Технология выплавки технического кремния / ред. О.М. Катков. Иркутск: ЗАО «Кремний», 1999. 244 с.

[2] Немчинова Н.В., Клёи В.Э. Кремний: свойства, получение, применение. Иркутск: ИрГТУ, 2008. $272 \mathrm{c}$.

[3] Немчинова Н.В. Поведение примесных элементов при производстве и рафинировании кремния. М.: Академия естествознания, 2008. 272 с.

[4] Попов С. И. Металлургия кремния в трехфазных рудно-термических печах. Иркутск: ЗАО «Кремний», 2004. $237 \mathrm{c}$.

[5] Рагулина Р.И., Емлин Р.И. Электротермия кремния и силумина. М.: Металлургия, 1972. $239 \mathrm{c}$.

[6] Reed S. J. B. Electron Microprobe Analysis. Cambridge London. New York. Melbourne, 1975. $306 \mathrm{p}$.

[7] Немчинова Н.В. // Известия вузов. Прикладная химия и биотехнология. 2012. № 1(2). С. 129-134.

[8] Немчинова Н.В., Удалов Ю.П., Клёи В.Э., Тютрин А.А. // Тезисы доклада VII Междунар. конф. и VI Школы молодых ученых и специалистов по актуальным проблемам физики, материаловедения, технологии и диагностики кремния, нанометровых структур и приборов на его основе «КРЕМНИЙ-2010». Нижний Новгород, 2010. С. 59.

[9] Тютрин А.А. // Системы. Методы. Технологии. 2013. № 2 (18). С. 110-113. 